\title{
Non-syndromic multiple impacted teeth: two case reports
}

\author{
Mohadeseh Delavarian ${ }^{1}$, Fatemeh Delavarian ${ }^{2}$, Mohammad Moslem Imani ${ }^{3}, * \mathbb{C}$
}

${ }^{1}$ Department of Orthodontics, Kerman University of Medical Sciences, Kerman, Iran

${ }^{2}$ Student Research Committee, Kerman University of Medical Sciences, Kerman, Iran

${ }^{3}$ Department of Orthodontics, Faculty of Dentistry, Kermanshah University of Medical Sciences, Kermanshah, Iran

\section{Correspondence}

Mohammad Moslem Imani Department of Orthodontics, Faculty of Dentistry, Kermanshah University of Medical Sciences, Kermanshah, Iran

Email: mmoslem.imani@yahoo.com History

- Received: 04 September 2018

- Accepted: 15 October 2018

- Published: 13 November 2018

DOI :

https://doi.org/10.15419/bmrat.v5i1 1.497

\section{Check for updates}

\section{Copyright}

(-) Biomedpress. This is an openaccess article distributed under the terms of the Creative Commons Attribution 4.0 International license.

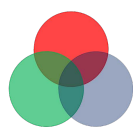

\begin{abstract}
Multiple impacted permanent teeth is a rare finding and often associated with systemic diseases or some rare syndromes. This article reports two Iranian cases with multiple impacted teeth without systemic disease or syndromes. The first patient, a 17-year-old male, had 18 unerupted teeth and 9 unerupted supernumerary teeth. The second patient, a 16-year-old female, had 14 unerupted teeth. In these cases, an interdisciplinary approach between orthodontist, oral surgeon and prosthodontist is required to achieve optimum facial aesthetics and functional occlusion.
\end{abstract}

Key words: Impacted teeth, Non-Syndromic, Supernumerary teeth

\section{INTRODUCTION}

In normal dental development, permanent teeth will erupt to their functional occlusion and replace their successor teeth. Teeth that cease to erupt before emergence are known as impacted teeth. Impaction is one of the most common dental problems seen among the eruption disorders ${ }^{1}$. Common reasons in the etiology of impacted teeth include lack of space due to crowding or early loss of deciduous teeth, prolonged retention of deciduous teeth, abnormal position of tooth bud, excessive fibrous tissue, ankylosis and cystic formation ${ }^{2-5}$. Impaction of an individual tooth is a common condition and maxillary canine exhibits the highest incidence of impaction and occurs in $1 \%$ to $3 \%$ of the population ${ }^{6-8}$. However, multiple impacted teeth is a rare finding and often associated with systemic diseases or some rare syndromes such as Cleidocranial dysplasia, Gardener's syndrome, Zimmerman-laband syndrome and Noonan's syndrome $e^{3,9-15}$. Impaction of multiple permanent teeth with no obvious etiology is a rare condition and few cases have been reported in the literature $^{5,16-21}$. In this study, we are presenting 2 cases with multiple impacted teeth in non-syndromic patients.

\section{CASE PRESENTATION}

\section{Case 1}

A 17-year-old male referred to our clinic with a chief complaint of multiple missing teeth. During the physical examination, the patient was of normal build and didn't reveal any sign of syndromes, mental retardation or skeletal abnormalities. On intraoral examination, he had retained deciduous teeth in both jaws with no eruption of permanent teeth. The patient was advised radiographic investigation in the form of panoramic. The panoramic radiograph of the patient revealed multiple impacted permanent teeth in the maxilla and mandible, retained deciduous teeth and multiple supernumerary teeth in the maxilla and mandible (Figure 1, Table 1).

Nine supernumerary teeth were observed in the panoramic radiograph, two in the maxilla and seven in the mandible. It was planned to extract retained deciduous teeth, surgical removal of supernumerary teeth, surgical exposure of permanent impacted teeth and assisting eruption of impacted teeth by orthodontic traction. If the patient doesn't respond to the orthodontic traction, surgical removal of impacted teeth and prosthodontic treatment is required.

\section{Case 2}

A 16-year-old female referred to our clinic with a chief complaint of multiple missing teeth. During physical examination the patient was of normal build and didn't show any sign of syndromes, mental retardation or skeletal abnormalities. Intraoral examination revealed that the patient's maxilla and mandible was partially edentulous. The patient was advised radiographic investigation in the form of panoramic and lateral cephalometric. Analysis of the lateral cephalometric radiograph revealed a skeletal class 1 malocclusion and anterior open bite. The panoramic radiograph of the patient demonstrated multiple impacted teeth in the maxilla and mandible (Figure 2, Table 2) It was planned to assist the eruption of impacted teeth by surgical exposure and orthodontic traction. If the patient doesn't respond to the orthodontic traction, 
Table 1: Unerupted teeth (case 1)

\begin{tabular}{ll}
181514131211 & 212223242528 \\
4843 & 32333438 \\
\hline
\end{tabular}

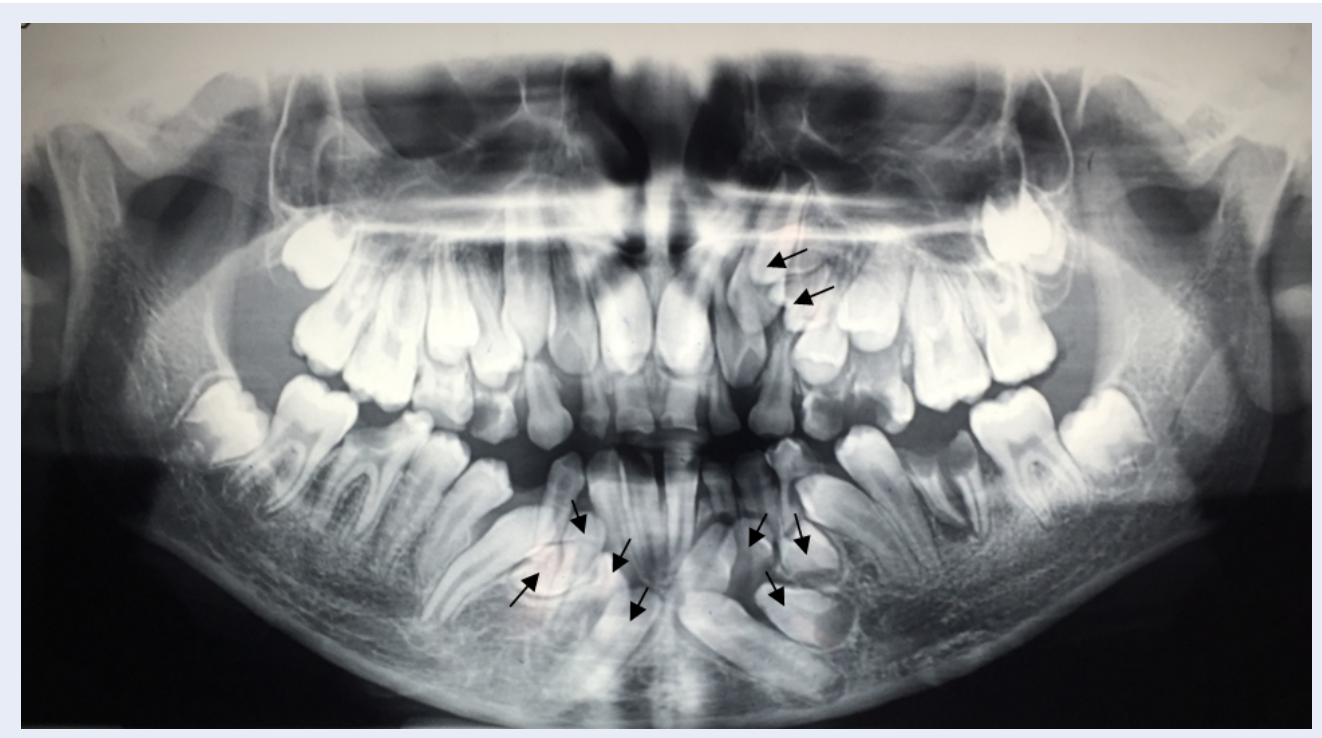

Figure 1: Panoramic radiograph showing retained deciduous and impacted permanent and supernumerary teeth (marked with arrows).

Table 2: Unerupted teeth

(case 2)

\begin{tabular}{ll}
\hline 181312 & 21222328 \\
48434241 & 313238 \\
\hline
\end{tabular}

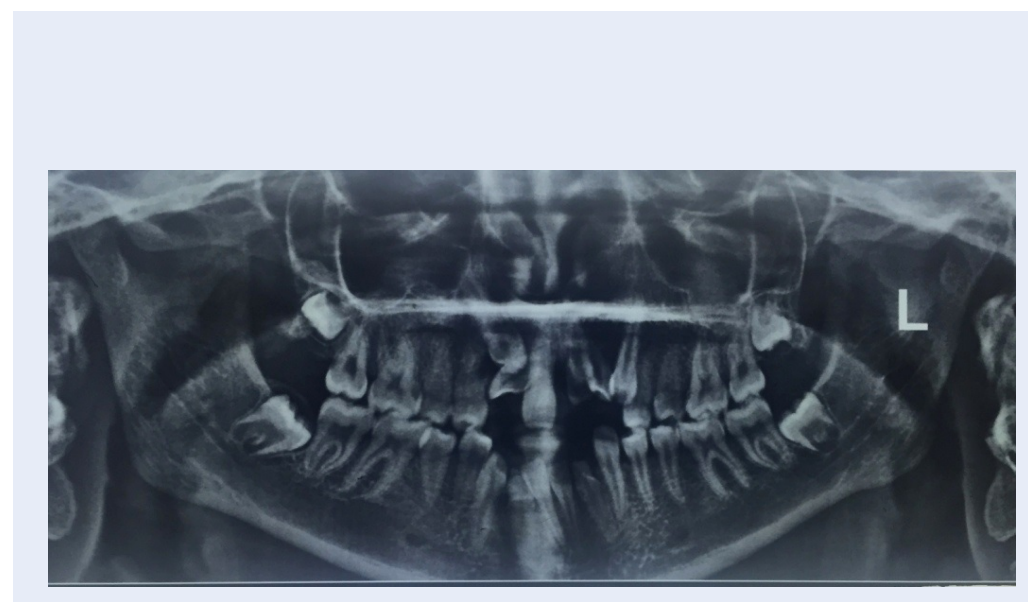

Figure 2: Panoramic radiograph showing multiple impacted teeth. 
surgical removal of impacted teeth and prosthodontic treatment is required.

\section{DISCUSSION}

Multiple impacted teeth are a rare condition and usually present in some syndromes. Impacted teeth are those prevented from eruption by some physical barrier in their path of eruption. Common reasons in the etiology of impacted teeth include lack of space due to crowding or early loss of deciduous teeth, prolonged retention of deciduous teeth, abnormal position of tooth bud, excessive fibrous tissue, ankylosis and cystic formation ${ }^{2-5}$. Impaction of maxillary canine and third molar is a common finding, however in present cases there were impaction of maxillary central and lateral incisors along with canines and third molars. In this circumstance, systemic disorder or some rare syndromes such as cleidocranial dysplasia, Gardener's syndrome, Zimmerman-laband syndrome and Noonan's syndrome should be detected ${ }^{9-16}$. In our cases, no features of any disorder or syndrome were diagnosed and syndromes were ruled out. Further investigation and medical history of patient didn't show any sign of metabolic disorders like vitamin D deficiency. The supernumerary teeth can lead to multiple complications such as delayed teeth eruption, failure of teeth to erupt, pathological changes and root resorption ${ }^{21}$. In case 1 , it seems that over retained deciduous teeth along with multiple supernumerary teeth might have resulted in multiple impactions of permanent teeth. According to root development of the adjacent teeth, it was decided to extract retained deciduous teeth and surgical removal of supernumerary teeth, and then monitor the impacted teeth until the spontaneous eruption occurs. If eruption doesn't occur, surgical exposure of permanent impacted teeth and assisting eruption of impacted teeth by orthodontic traction should be needed. In case 2 , it seems that impaction of teeth is probably caused by lack of space in the dental arch and rotation of tooth buds which some of the most common causes are contributing to impaction. In these cases, an interdisciplinary approach between orthodontist, oral surgeon and prosthodontist is required to achieve optimum facial aesthetics and functional occlusion. If ankylosis has occurred and the patient doesn't respond to the orthodontic traction, surgical removal of impacted teeth and prosthodontics treatment is required.

\section{CONCLUSIONS}

The simultaneous occurrence of multiple supernumerary and impaction of permanent teeth can occur in both sexes with healthy systemic condition without syndromic symptoms. Occasionally, the presence of a large number of over retained primary teeth may indicate a more complex condition in the pathway of permanent teeth, such as supernumerary teeth that have blocked the eruption way, under which early radiographic examination is necessary.

\section{ETHICS APPROVAL AND CONSENT TO PARTICIPATE}

Not to be applied.

\section{Competing interests}

The authors declare that they have no conflicts of interest.

\section{Funding}

None.

\section{Authors' contributions}

Mohadeseh Delavarian \& Fatemeh Delavarian: Literature search, Clinical studies, Data acquisition, and Data analysis

Mohammad Moslem Imani: Manuscript preparation, Manuscript review, and Guarantor

Mohadeseh Delavarian: Concepts, Design, Definition of intellectual content, Literature search, Manuscript editing

Mohadeseh Delavarian \& Mohammad Moslem Imani: Manuscript editing

\section{REFERENCES}

1. Sivapathasundharam B, Einstein A. Non-syndromic multiple supernumerary teeth: report of a case with 14 supplemental teeth. Indian Journal of Dental Research. 2007;18:144. Available from: Doi:10.4103/0970-9290.33794.

2. Kumar GS. Orbans Oral Histology and Embryology. In: null. India: Elsevier; 2009. .

3. Yalcin S, Gurbuzer B. Multiple impacted teeth in the maxilla. Oral Surgery, Oral Medicine, and Oral Pathology. 1993;76:130. Available from: Doi:10.1016/0030-4220(93)90310-z.

4. Sivakumar A, Valiathan A, Gandhi S, Mohandas AA. Idiopathic failure of eruption of multiple permanent teeth: report of 2 adults with a highlight on molecular biology. American Journal of Orthodontics and Dentofacial Orthopedics. 2007;132:687-92. null. Available from: DOI:10.1016/j.ajodo. 2006.04.034.

5. Tanaka E, Kawazoe A, Nakamura S, Ito G, Hirose N, Tanne Y. An adolescent patient with multiple impacted teeth. The Angle Orthodontist. 2008;78:1110-8. null. Available from: Doi:10. 2319/121007-581.1.

6. Bishara SE. Clinical management of impacted maxillary canines. Seminars in Orthodontics. 1998;4:87-98. null. Available from: Doi:10.1016/s1073-8746(98)80006-6.

7. Peck S, Peck L, Kataja M. The palatally displaced canine as a dental anomaly of genetic origin. The Angle Orthodontist. 1994;64:249-56. null.

8. McDonald F, Yap WL. The surgical exposure and application of direct traction of unerupted teeth. American Journal of Orthodontics. 1986;89:331-40. null. Available from: Doi:10.1016/0002-9416(86)90056-4 
9. Gorlin RJ, Cohen MM, Hennekam RC. Syndromes of the Head and Neck Fourth. In: Syndromes of the Head and Neck Fourth. Oxford University Press; 2001 . .

10. Babu V, Nagesh KS, Diwakar NR. A rare case of hereditary multiple impacted normal and supernumerary teeth. The Journal of Clinical Pediatric Dentistry. 1998;23:59-61.

11. Cooper SC, Flaitz CM, Johnston DA, Lee B, Hecht JT. A natural history of cleidocranial dysplasia. American Journal of Medical Genetics. 2001;104:1-6. Available from: DOI:10.1002/ ajmg.10024.

12. Kirson LE, Scheiber RE, Tomaro AJ. Multiple impacted teeth in cleidocranial dysostosis. Oral Surgery, Oral Medicine, and Oral Pathology. 1982;54:604. Available from: Doi:10.1016/00304220(82)90204-3.

13. Sharma A. A rare non-syndrome case of concomitant multiple supernumerary teeth and partial anodontia. The Journal of Clinical Pediatric Dentistry. 2001;25:167-9. Available from: DOI:10.17796/jcpd.25.2.k4617k5126205k46.

14. Chodirker BN, Chudley AE, Toffler MA, Reed MH, Opitz JM, Reynolds JF. Zimmerman-Laband syndrome and profound mental retardation. American Journal of Medical Genetics. 1986;25:543-7. Available from: DOI:10.1002/ajmg. 1320250317.

15. Bakaeen G, Scully C. Hereditary gingival fibromatosis in a family with the Zimmermann-Laband syndrome. Journal of Oral
Pathology \& Medicine. 1991;20:457-9. null. Available from: DOI:10.1111/j.1600-0714.1991.tb00438.x.

16. Sujatha G, Sivapathasundharam B, Sivakumar G, Nalinkuma S, Ramasamy M, Prasad TS. Idiopathic multiple impacted unerupted teeth: case report and discussion. Journal of Oral and Maxillofacial Pathology : JOMFP. 2012;16:125-7. null. Available from: Doi:10.4103/0973-029x.92989.

17. Guruprasad Y, Naik RG. Multiple impacted teeth in a nonsyndromic patient. SRM J Res Dent Sci. 2012;3:279-80. null. Available from: Doi:10.4103/0976-433x.114972.

18. Saluja H, Mahindra U, Gaikwad PT, Lote KR. Multiple impacted teeth in maxilla in a young non syndromic patient : A rare oc currence: A case report with review of literature. Pravara Medical Review. 2012;4:23-4

19. Bayar GR, Ortakoglu K, Sencimen M. Multiple impacted teeth: report of 3 cases. European Journal of Dentistry. 2008;2:73-8.

20. Xue DJ, Xue F. Combined Orthodontic-surgical Treatment for Skeletal Class III Malocclusion with Multiple Impacted Permanent and Supernumerary Teeth: case Report. The Open Dentistry Journal. 2014;8:43-8. null. Available from: Doi: $10.2174 / 1874210601408010043$.

21. Saluja KS, Singh B, Bhatia TK. An atypical case of nonsyndromic multiple impacted supernumerary teeth - a case report. International Journal of Contemporary Medical Research. 2016:3:1423-5. 